\title{
Assessing the suitability of non-invasive methods to monitor interspecific interactions and breeding biology of the South Georgian diving petrel (Pelecanoides georgicus)
}

\author{
JOHANNES H. FISCHER \\ IGOR DEBSKI \\ GRAEME A. TAYLOR \\ Department of Conservation, PO Box 10420, Wellington 10420, New Zealand
}

School of Biological Sciences, Victoria University of Wellington, PO Box 600, Wellington 6140, New Zealand

HEIKO U. WITTMER

School of Biological Sciences, Victoria University of Wellington, PO Box 600, Wellington 6140, New Zealand

\begin{abstract}
We assessed the impact of interspecific interactions on the breeding success of the South Georgian diving petrel (Pelecanoides georgicus; SGDP), a Nationally Critical seabird species, by monitoring 20 burrows at Codfish Island (Whenua Hou), with remote cameras. Additionally, we tested the utility of remote cameras to study the breeding biology and activity patterns of the SGDP by pairing 5 remote cameras with RFID readers. We recorded 7 different species at SGDP burrow entrances. The common diving petrel ( $P$. urinatrix) likely caused two monitored burrows to fail. These results suggest that remote cameras are useful tools to study such interactions. However, the cameras had extremely low SGDP detection rates (mean $=10.86 \%$; se $=7.62 \%$ ) when compared to RFID readers. These low detection rates may be explained by the small body size and the speed at which SGDPs enter/leave burrows. Therefore, remote cameras, or at least the model and setup we used, appear unsuitable to study breeding biology and activity patterns in this seabird species.
\end{abstract}

Fischer, J.H.; Debski, I.; Taylor, G.A.; Wittmer, H.U. 2017. Assessing the suitability of non-invasive methods to monitor interspecific interactions and breeding biology of the South Georgian diving petrel (Pelecanoides georgicus). Notornis 64 (1): $13-20$.

Key words Breeding biology; interspecific interactions; South Georgian diving petrel; Pelecanoides georgicus; common diving petrel; Pelecanoides urinatrix; Radio Frequency Identification; remote cameras

\section{INTRODUCTION}

Seabirds are one of the most threatened taxonomic groups on the planet (Croxall et al. 2012). Due to their life history, seabirds are threatened on land and at sea (Taylor 2000). Introduced mammalian predators, such as rats (Rattus ssp.), are considered a detrimental terrestrial threat to seabirds in general, and smaller species in particular (Jones et al. 2007). In New Zealand, home to one of the most

Received 5 December 2016; accepted 22 December 2016 Correspondence: johannesfischer@live.nl diverse and threatened seabird communities on the planet, introduced mammals have severely reduced the abundance and distribution of seabird species and populations (Taylor 2000; Croxall et al. 2012). Substantial effort is invested into mitigating the impacts of introduced mammals through islandwide eradications (Towns \& Broome 2003; Jones et al. 2016).

Besides introduced mammals, the already reduced seabird populations in New Zealand face several other threats onshore, including habitat loss and effects of stochastic events (Taylor 2000). 
Furthermore, interspecific interactions, other than predation by introduced species, can impact seabird populations (Gummer et al. 2015). Various cases of negative interactions with native species have been documented, including morepork (Ninox novaeseelandiae) and tuatara (Sphenodon punctatus) predation (Trainor 2008; Corkery et al. 2015), non-predatory attacks on petrel chicks by Campbell Island teal (Anas nesiotis) (R. Sagar pers. comm. 2016), and competition between various seabird species for nest-sites (Sullivan \& Wilson 2001; Friesen et al. 2016). In some instances, such interactions have contributed to substantial population declines (Gummer et al. 2015).

Many seabird species in New Zealand breed in burrows, restricting our ability to study breeding biology and activity patterns; however, several techniques can be used to overcome this limitation. The simplest method to monitor activity patterns is the use of stick palisades (a row of sticks in front of the burrow entrance), but this method is prone to false positives (Taylor et al. 2012). An approach to study both activity patterns and breeding biology is the instalment of study burrows (the placement of a lid into a burrow that allows the access to brood chambers). However, the use of study burrows is labour intensive, invasive and may not always be feasible (Blackmer et al. 2004; Taylor et al. 2012). The development of new technologies has produced less invasive study methods (Young 2013). For example, Radio Frequency Identification (RFID) readers, also known as Passive Integrated Transponder (PIT) readers, have been used to study burrowing seabirds (e.g., Zangmeister et al. 2009; Taylor et al. 2012). RFID readers allow the automated monitoring at burrow entrances of individuals equipped with RFID tags. Remote cameras are also increasingly being used to monitor burrows and assess breeding biology and activity patterns (Taylor et al. 2012; Dilley et al. 2015). However, the use of remote cameras poses considerable challenges, as large amounts of footage need to be viewed and assessed (Johnston et al. 2003). One potential advantage of using remote cameras is the opportunity they provide to assess interspecific interactions at burrows (Dilley et al. 2015).

The South Georgian diving petrel (Pelecanoides georgicus; SGDP) is a small, burrowing seabird which is classified as Nationally Critical in New Zealand (Robertson et al. 2013), due to its distribution being currently limited to Codfish Island (Whenua Hou) and an estimated population of 150 individuals (Taylor 2000; 2013). Introduced mammalian species are likely to have been the main cause of the historic population declines of the SGDP, extirpating the species throughout most its historic range (Taylor 2000; Fischer et al. 2017). While Codfish Island is now free of introduced mammalian predators following eradication efforts (Middleton 2007), other potential threats are present. For instance, dune erosion caused by storms continues to threaten the SGDP colony (Fischer et al. in press). Also, interactions with other species may also reduce the reproductive success of this species. For example, the SGDP may suffer from competition for nest-sites with the common diving petrel (P. urinatrix; CDP) (Fischer et al. in press). In addition, morepork predation has been recorded anecdotally (Trainor 2008). Currently available data on the SGDP breeding biology and activity patterns are either anecdotal (Taylor \& Cole 2002; Cole 2004; Trainor 2008) or originate from populations from different oceans (Payne \& Prince 1979; Marchant \& Higgins 1990).

To better understand interspecific interactions affecting SGDP breeding success (i.e., producing fledglings) on Codfish Island, we monitored 20 occupied SGDP burrows with remote cameras during the presumed chick rearing period (Taylor 2013). In addition, to assess the utility of remote cameras to monitor and study the breeding biology and activity patterns of the SGDP, we paired 5 remote cameras with RFID readers.

\section{MATERIAL AND METHODS}

\section{Study area}

In New Zealand, SGDP distribution is limited to a single colony at the Sealers Bay dunes $\left(-46.766^{\circ}\right.$, $167.645^{\circ}$ ) on Codfish Island, approximately $3 \mathrm{~km}$ west of Stewart Island (Fischer et al. in press). Our study area encompassed the entire Sealers Bay dunes (approximately $100 \mathrm{~m}$ x $900 \mathrm{~m}$ ) and included all previous SGDP nest-sites (Taylor \& Cole 2002).

\section{Burrow occupancy and breeding success}

SGDP burrows were searched for over a period of 10 days in early November 2015, when SGDPs were incubating (Taylor \& Cole 2002; Cole 2004; Trainor 2008; Taylor 2013). The occupancy of detected burrows was determined using stick palisades, which were checked twice a week. To account for false positives (Taylor et al. 2012), only burrows with three or more records of disturbed palisades were considered as active. Playback and hand captures were then used to confirm that SGDPs were the species occupying the burrows (Taylor \& Cole 2002). To assess burrow abandonment, stick palisades were checked twice a week until late December 2015.

During a repeat visit in late January 2016, we assessed the success (i.e., fledglings present) of all SGDP burrows using daily monitoring with stick palisades (Taylor \& Cole 2002); when repeated signs of activity (disturbed palisades) were recorded, burrows were assumed to have chicks close to 
fledging. If active burrows then ceased to show signs of activity in late January 2016, they were assumed to have successfully produced fledglings.

\section{Remote camera deployment}

In early November 2015, a pilot study using 10 Bushnell Trophy Cam $^{\mathrm{TM}}$ Trail cameras (Model 119436; Bushnell Outdoor Technology 2011) was conducted to assess the most suitable settings for monitoring SGDP burrows. As this model of camera cannot be programmed to record a specific time interval, the cameras were checked daily over a period of 10 days. This initial round of testing showed that the cameras recorded almost indefinitely throughout the day, potentially due to the high temperature differences in dunes affecting the passive infrared sensor. This caused memory cards to fill up within days. In addition, SGDPs appeared to enter/leave their burrows in seconds, without lingering at burrow entrances. We therefore decided to use the following settings for long-term monitoring at SGDP burrows as a compromise between data collection and data storage: 5 second video recordings, followed by a 60 second break, and "medium" sensitivity (Bushnell Outdoor Technology 2011).

The subsequent long-term monitoring was conducted at 20 burrows from mid-November 2015 to late January 2016 (54-61 nights); this period covered the entire presumed chick rearing period (Taylor 2013). A total of 20 cameras were deployed at occupied SGDP burrows. Of the 20 cameras, 15 were placed at randomly selected burrows, while 5 were placed at burrows occupied by SGDPs fitted with RFID tags (see below). The cameras were set up $1.5 \mathrm{~m}$ from burrow entrances. All memory cards were replaced and data downloaded on a biweekly basis. Broken or malfunctioning cameras were replaced when necessary. A cumulative total of 1,121 monitoring nights was recorded for the 20 cameras.

\section{Assessment of remote cameras for monitoring}

We captured 5 SGDPs by hand at burrow entrances and equipped the birds with RFID tags to assess detection rates of remote cameras. A $12 \mathrm{~mm} \mathrm{x}$ $2.5 \mathrm{~mm}$ RFID tag (Allflex ${ }^{\mathrm{tm}} \mathrm{P} / \mathrm{N}$, ISO FDX-B) was attached on the left tarsus using wrap-around colour bands. Tagged birds were marked with a lateral stripe on the crown using Wite-Out ${ }^{\circledast}$ to allow individual recognition on remote cameras.

After equipping 5 SGDPs with RFID tags, we deployed a remote camera and RFID reader in a paired setup at the 5 burrows. The custom-made RFID readers, as used by Taylor et al. (2012), were set to record from $2100 \mathrm{~h}$ to $0600 \mathrm{~h}$ (approximately sunset to sunrise). To ensure maximum detectability, the RFID readers were programmed to read for tags every 0.1 second. Furthermore, to ensure appropriate correspondence with the RFID tags $(134,200 \mathrm{~Hz})$, customised RFID reader antennas were built using transformer-winding copper wire on site following Taylor et al. (2012). The reading frequency of the antennas was checked weekly to ensure it remained constant (Taylor et al. 2012). The RFID readers ran on $12 \mathrm{~V}$ batteries which were replaced on a weekly basis. SGDP burrows with RFID readers were monitored from mid-November to late December 2015 (28-34 nights).

\section{Data analysis}

To assess interspecific interactions at SGDP burrows, we checked all video footage recorded between sunset and sunrise, as SGDPs arrive at their burrows after sunset and return to sea before sunrise (Taylor \& Cole 2002). We recorded activities of all species detected at SGDP burrow entrances and categorised activities based on the interaction with the burrow entrance or the SGDPs: neutral (e.g. no perceivable interaction), investigative (e.g., inspecting the burrow entrance) and interfering (i.e. competition with or predation of the SGDP). We considered multiple videos of a certain species (other than the SGDP) in a single night as one record. To assess the effect of these interactions on SGDP breeding success, we linked the recorded interaction to stick palisades and camera records.

To assess the use of remote cameras to monitor the breeding biology of SGDPs, we compared the time RFID readers recorded SGDP activity with the time of remote camera records. SGDP records with 5 minutes of overlap between remote cameras and RFID readers were considered to pertain to the same record, as both RFID readers and remote cameras can have some error in recording time. Multiple RFID detections within 60 seconds were reduced to one record, to account for the 60 second break of the remote cameras. We considered RFID reader detections as a correct representation of activity (Taylor et al. 2012) and calculated remote camera detection rates as a percentage of the RFID detection rates. SGDPs recorded by cameras but not by RFID readers were assumed to pertain to the untagged partner if the Wite-Out ${ }^{\circledast}$ marking was not visible. In addition, as SGDPs may leave burrows too quickly to be recorded on the remote cameras, while still triggering the camera (Model 119436 has a response period of 1 second; Bushnell Outdoor Technology 2011), we considered videos without SGDPs that were recorded at the same time as RFID detected SGDP activity as near-hits. We combined percentages of SGDP detections and near-hits to assess the maximum detection rates of the cameras. Furthermore, we categorised SGDP activity on videos as entering or leaving.

Due to the small sample sizes, statistical analyses 


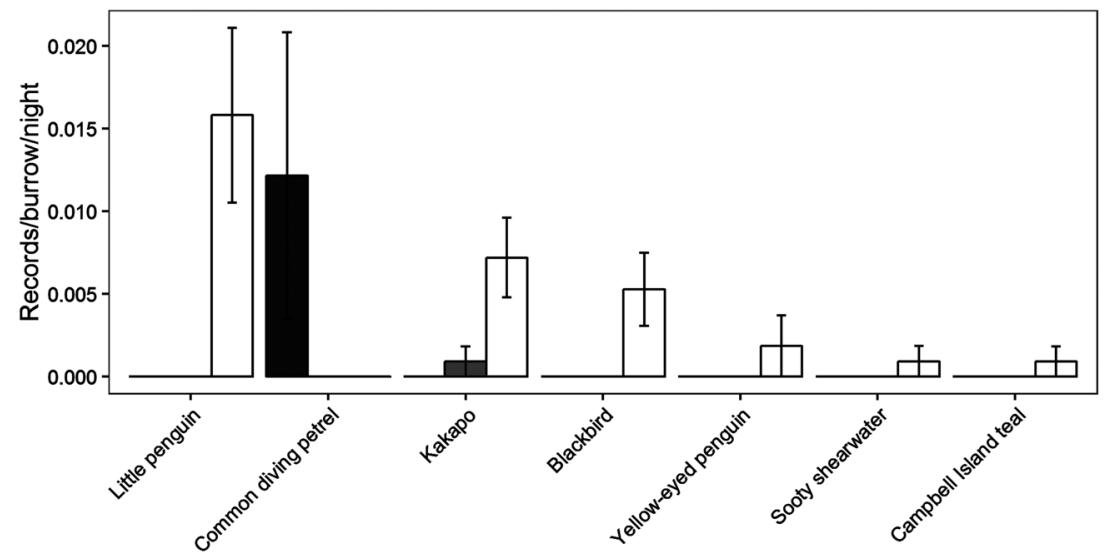

Fig. 1. Nature and frequency (mean $\pm s e$ ) of nocturnal interspecific interactions at South Georgian diving petrel burrows, as recorded with remote cameras during the chick rearing phase. Interfering behaviour black, investigative behaviour grey, neutral behaviour white.

were not conducted. Instead, simple percentage calculations and graphical visualisations using Program R (R Development Core Team 2016) with the ggplot2 package (Wickham 2009) were undertaken.

\section{RESULTS}

\section{Interactions at burrows}

We obtained 20,897 videos at 20 SGDP burrows during mid-November 2015 to late January 2016 (the presumed chick rearing period). Of those videos, 1,616 were recorded at night and these revealed 88 videos of 7 different species. The most commonly recorded species at night were little penguin (Eudyptula minor) (14 records at 9 burrows), CDP (14 records at 2 burrows), kakapo (Strigops habroptilus) (9 records at 7 burrows) and blackbird (Turdus merula) (6 records at 5 burrows). Yellow-eyed penguin (Megadyptes antipodes) were recorded at 1 burrow (3 records). Sooty shearwater (Puffinus griseus) and Campbell Island teal were rare and only recorded on a single occasion at 1 burrow. Most interspecific interactions recorded at SGDP burrows were neutral (Fig. 1). However, kakapo occasionally showed investigative behaviour (Fig. 2A). More importantly, all records of CDP showed interfering behaviour, which included CDPs entering SGDP burrows, CDPs showing signs indicative of physical conflict, and CDPs collecting nesting material (Fig. 2B).

Ten of the 20 monitored SGDP burrows did not produce fledglings. The nest failure of 2 burrows appeared to be linked to interference from CDPs.
Prior to the CDP records, adult SGDPs with brood patches were captured in both burrows. No SGDP activity was detected after the CDP records. For the other 8 unsuccessful SGDP burrows, no intraspecific competition was recorded and the cause of nest failure or abandonment remained unidentified.

\section{Detection rate of remote cameras}

During the study period, RFID readers detected 3338 and 8-12 SGDP records at successful burrows ( $n$ $=3)$ and unsuccessful burrows $(n=2)$ respectively. The nocturnal SGDP activity recorded by RFID readers showed 2 activity peaks around $2300 \mathrm{~h}$ and $0300 \mathrm{~h}$ (Fig. 3). Remote cameras detected 2-13 SGDP records at successful burrows and none at unsuccessful burrows. Of the activities detected by remote cameras, only 2 pertained to birds leaving their burrow, 15 related to birds entering, and 1 to a bird leaving and re-entering the burrow. Furthermore, the activity patterns revealed by remote cameras differed substantially from the patterns revealed by RFID readers.

When compared to RFID readers, the detection rates of remote cameras were extremely low. Detection rates ranged from $0.00 \%$ to $40.63 \%$ (mean $=10.86 \%$; se $=7.62 \%$ ). Near-hit rates were slightly higher and ranged from $0.00 \%$ to $47.49 \%$ (mean $=24.94 \%$; $s e=8.99 \%$ ) of RFID reader detections. When combined, the maximum detection rates ranged from $0.00 \%$ to $62.50 \%$ (mean $=35.81 \%$; se $=16.60 \%$ ). No remote camera records of marked birds remained undetected by the RFID readers, indicating accurate detection rates of RFID readers. 


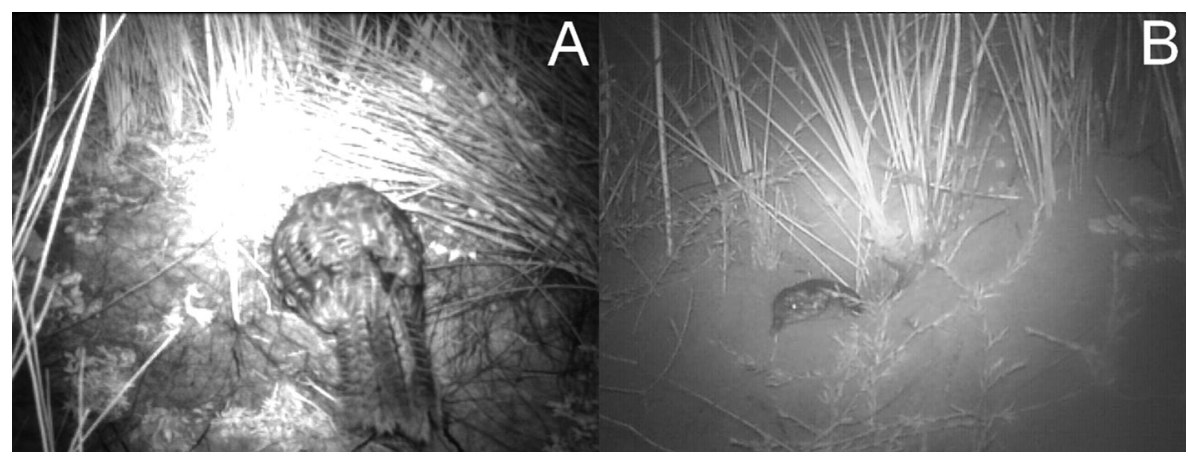

Fig. 2. Investigative and interfering behaviour of two species at South Georgian diving petrel burrows recorded by remote cameras: (2A) kakapo investigating a burrow entrance; (2B) common diving petrel in the burrow entrance with signs of a previous conflict (ruffled feathers on the side of the head).

\section{DISCUSSION}

Our results show that various species do occur at, and interact with, SGDPs and their burrows on Codfish Island; but only the CDP showed interfering behaviour. These results suggest that remote cameras may be a useful tool to assess the impact of adverse interspecific interactions at SGDP burrows. However, our results also showed that remote camera detection rates of SGDP activity were extremely low and resulted in questionable documentation of activity patterns. Therefore, this non-invasive monitoring method appears unsuitable to study breeding biology and activity patterns in the SGDP, at least with the model and setup used in this study.

Two monitored SGDP burrows appear to have been negatively affected by CDP behaviour. Both burrows may have been CDP burrows and only sporadically visited by non-breeding SGDPs. However, the presence of brood patches on the SGDPs present in these burrows indicates a breeding attempt (Rayner et al. 2013). The lack of SGDP activity following CDP records, as well as CDPs collecting nesting material and showing signs of physical conflict, suggest that these SGDP burrows were taken over by CDPs, and therefore likely caused SGDP nest failure. Currently, the CDP population on Codfish Island is very small (Fischer et al. in press) and thus the potential threat to SGDP from competition may be minor. Continued monitoring is needed to assess the CDP population trends within the Sealers Bay dunes and to quantify the potential negative effect on the SGDP. Previous observations suggested that the CDP may be more aggressive than the SGDP (Fischer et al. in press). If SGDP-CDP competition increases, management measures to reduce competition, for example the instalment of burrow flaps (Sullivan \& Wilson 2001; Gummer et al. 2015), may be required to safeguard the SGDP population.

Several other species besides CDPs were recorded at SGDP burrows; however, none showed any behaviour with negative effects on SGDP breeding success. Kakapo are known to have an inquisitive nature (Farrimond et al. 2006), and while investigative activity by this species was detected at SGDP burrows, it does not appear to pose a threat to SGDP breeding success. A single record of a Campbell Island teal showing neutral behaviour was documented. This species has been shown to be capable of reducing the breeding success of mottled petrel (Pterodroma inexpectata) through non-predatory attacks (R. Sagar pers. comm. 2016). However, the lack of interactions recorded indicates that teals are not currently impacting the SGDP, perhaps because of the small entrance size of SGDP burrows or because their breeding periods coincide (Heather \& Robertson 2015). While morepork predation on Codfish Island SGDP has previously been reported (Trainor 2008), the remote cameras used in this study did not record morepork throughout the SGDP chick rearing period. Consequently, it appears that morepork may not pose a substantial threat to the SGDP population.

As useful as remote cameras are to monitor interspecific interactions, the detection of SGDP 


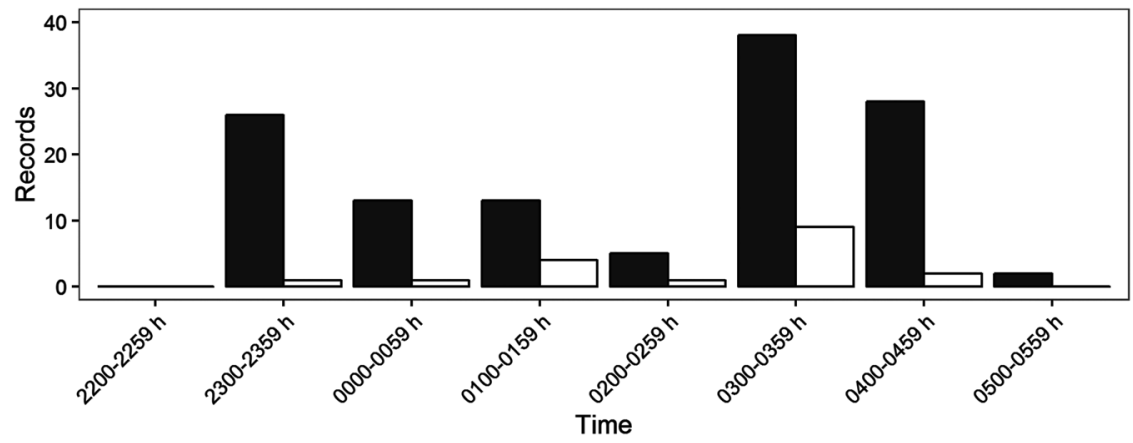

Fig. 3. Nocturnal activity of South Georgian diving petrels recorded by Radio Frequency Identification (RFID) reader (black) and remote cameras (white).

activity in this study was very low and resulted in inaccurate documentation of activity patterns. Remote cameras of the model and setup used here were thus not suitable to monitor the breeding activities of the SGDP. Potentially, the detection rates were low because SGDPs are small and enter/ leave their burrows quickly. The higher detection rate of SGDPs entering burrows may be explained by the need to clear the burrow entrances of accumulated sand. The camera model and setup we used may be more advantageous for other small seabird species such as the New Zealand storm petrel (Fregetta maoriana), which is even smaller than the SGDP (Heather \& Robertson 2015), but appears to spend more time around the burrow entrance and its breeding biology has been studied using cameras (Rayner et al. 2015). The use of remote cameras to study breeding biology and activity patterns in small, burrowing seabirds should thus be considered with care.

The use of RFID readers for breeding biology monitoring could be further investigated, but study burrows are likely to be the most advantageous method for burrowing petrels. The disadvantage of RFID readers is that they do not show directionality and thus limit data analysis. Furthermore, the weekly battery changes are labour-intensive and not ideal for long-term monitoring on remote islands. These shortcomings can be overcome by using paired antennas and tagging both birds of a pair to assess movement directionality, and by using solar panels to power RFID readers (Taylor et al. 2012). However, neither RFID readers nor remote cameras provide data on feeding portions and chick growth rates as both methods are limited to assessing activity at the burrow entrance.
Consequently, the instalment of study burrows should be considered to study the breeding biology of the SGDP more in-depth. This technique may be labour intensive, invasive and potentially limited to a selected suite of SGDP burrows in the most stable soils, but this technique will likely provide the most useful breeding biology data. Considering the precarious state of the SGDP in New Zealand, further studies appear necessary, especially since many conservation management strategies and risk assessments require detailed breeding biology data (Miskelly \& Taylor 2004; Miskelly et al. 2009; Armstrong \& Reynolds 2012).

\section{ACKNOWLEDGMENTS}

This research was generously supported by the Birds NZ Research Fund of the Ornithological Society of New Zealand (OSNZ), the Centre for Biodiversity and Ecological Restoration (CBRE), and the Hutton's Shearwater Charitable Trust. We are indebted to Stu Cockburn for providing RFID equipment and valuable insights on its use. The Ngāi Tahu, DOC Southern Islands and Kakapo Recovery have our gratitude for allowing the visits to Codfish Island (Whenua Hou). We are grateful to Juliet O'Connell and Graeme Miller for their help in the field. We thank Victor Anton, Leigh Bull, Phil Battley, Ellen Irwin, Nicola Nelson, and two anonymous reviewers for improving previous versions of this manuscript.

\section{LITERATURE CITED}

Armstrong, D.P.; Reynolds, M.H. 2012. Modelling reintroduced populations. The state of the art and future directions. In: Ewen, E.G.; Armstrong, D.P.; Parker, K.A.; Seddon, P.J. (eds.). Reintroduction Biology. Oxford, John Wiley \& Sons Ltd.

Blackmer, A.L.; Ackerman, J.T.; Nevitt, G.A. 2004. Effects of investigator disturbance on hatching success and 
nest-site fidelity in a long-lived seabird, Leach's storm petrel. Biological Conservation 116: 141-148.

Bushnell Outdoor Technology. 2011. Bushnell Trophy Cam ${ }^{T M}$ Instruction Manual (Model\#s: 119436/119446/119456). Bushnell Outdoor Products, Kansas, U.S.A.

Cole, R. 2004. Summary of South Georgian diving petrel field observations for 2003/04, Codfish Island/Whenua Hou. Invercargill, Department of Conservation.

Corkery, I.; Bell, B.D.; Nelson, N.J. 2015. Is the breeding behaviour of nesting seabirds influenced by the presence of a predatory reptile-the tuatara? Journal of the Royal Society of New Zealand 45: 21-30.

Croxall, J.P.; Butchart, S.H.M.; Lascelles, B.; Stattersfield, A.J.; Sullivan, B.; Symes, A.; Taylor, P. 2012. Seabird conservation status, threats and priority actions: a global assessment. Bird Conservation International 22: $1-34$.

Dilley, B.J.; Davies, D.; Bond, A.L.; Ryan, P.G. 2015. Effects of mouse predation on burrowing petrel chicks at Gough Island. Antarctic Science 27: 543-553.

Farrimond, M.; Elliott, G.P.; Clout, M.N. 2006. Growth and fledging of kakapo. Notornis 53: 112-115.

Fischer, J.H.; Hjorsvarsdottir, F.O.; Hiscock, J.A.; Debski, I.; Taylor, G.A.; Wittmer, H.U. 2017. Confirmation of the extinction of South Georgian diving petrels (Pelecanoides georgicus) on Enderby Island. Notornis 64: 48-51.

Fischer, J.H.; Debski, I.; Taylor, G.A.; Wittmer, H.U. (in press). Nest-site selection of South Georgian diving petrels on Codfish Island (Whenua Hou), New Zealand: implications for conservation management. Bird Conservation International.

Friesen, M.R.; James, R.R.; Mainland, M.; Gaskin, C.P. 2016. First record of a petrel species killed by penguins: outcome of competition for artificial nesting boxes. Notornis 63: 112-115.

Gummer, H.; Taylor, G.; Wilson, K.-J.; Rayner, M.J. 2015. Recovery of the endangered Chatham petrel (Pterodroma axillaris): a review of conservation management techniques from 1990 to 2010. Global Ecology \& Conservation 3: 310-323.

Haw, J.M.; Clout, M.N. 1999. Diet of morepork (Ninox novaeseelandiae) through New Zealand by analysis of stomach contents. Notornis 46: 333-345.

Heather, B.; Robertson, H. 2015. The field guide to the birds of New Zealand. New Zealand, Penguin Random House.

Johnston, R.B.; Bettany, S.M.; Ogle, R.M.; Aikman, H.A.; Taylor, G.A.; Imber, M.J. 2003. Breeding and fledging behaviour of the Chatham taiko (Magenta petrel) Pterodroma magentae and predator activity at burrows. Marine Ornithology 31: 193-197.

Jones, H.P.; Holmes, N.D.; Butchart, S.H.M.; Tershy, B.R.; Kappes, P.J.; Corkery, I.; Aguirre-Munoz, A.; Armstrong, D.P.; Bonnaud, E.; Burbidge, A.A.; Campbell, K.; Courchamp, F.; Cowan, P.E.; Cuthbert, R.J.; Ebbert, S.; Genovesi, P.; Howald, G.R.; Keitt, B.S.; Kress, S.W.; Miskelly, C.M.; Oppel, S.; Poncet, S.; Rauzon, M.J.; Rocamora, G.; Russell, J.C.; SamaniegoHerrera, A.; Seddon, P.J.; Spatz, D.R.; Towns, D.R.; Croll, D.A. 2016. Invasive mammal eradication on island results in substantial conservation gains. Proceedings of the National Academy of Sciences of the United States of America 113: 4033-4038.

Jones, H.P.; Tershy, B.R; Zavaleta, E.S.; Croll, D.A.; Keitt,
B.S.; Finkelstein, M.E.; Howald, G.R. 2007. Severity of the effects of invasive rats on seabirds: A global review. Conservation Biology 22: 16-26.

Marchant, S.; Higgins, P.J. 1990. Handbook of Australian, New Zealand $\mathcal{E}$ Antarctic Birds. Vol. 1 Ratites to ducks: Part A, Ratites to petrels. Melbourne, Oxford University Press.

Middleton, A. 2007. Two hundred years on Codfish Island (Whenua Hou). Southland Conservancy, Invercargill, Department of Conservation.

Miskelly, C.M.; Taylor, G.A. 2004. Establishment of a colony of common diving petrels (Pelecanoides urinatrix) by chick transfers and acoustic attraction. Етu 104: 205-211.

Miskelly, C.M.; Taylor, G.A.; Gummer, H.; Williams, R. 2009. Translocations of eight species of burrownesting seabirds (genera Pterodroma, Pelecanoides, Pachyptila and Puffinus: Family Procellaridae). Biological Conservation 142: 1965 - 1980.

Payne, M.R.; Prince, P.A. 1979. Identification and breeding biology of the diving petrels Pelecanoides georgicus and P. urinatrix exsul at South Georgia. New Zealand Journal of Zoology 6: 299-318.

R Development Core Team. 2016. R: A language and environment for statistical computing. Vienna, Austria, R Foundation for Statistical Computing (version 3.2.4). http://www.Rproject.org/.

Rayner, M.J.; Gaskin, C.P.; Stephenson, B.M.; Fitzgerald, N.B.; Landers, T.J.; Robertson, B.C.; Scofield, R.P.; Ismar, S.M.H.; Imber, M.J. 2013. Brood patch and sexratio observations indicate breeding provenance and timing in New Zealand storm-petrel Fregetta maoriana. Marine Ornithology 41: 107-111.

Rayner, M.J.; Gaskin, C.P.; Fitzgerald, N.B.; Baird, K.A.; Berg, M.M.; Boyle, D.; Joyce, L.; Landers, T.J.; Loh, G.G.; Maturin, S.; Perrimen, L.; Scofield, R.P.; Simm, J.; Southey, I.; Taylor, G.A.; Tennyson, A.J.D.; Robertson, B.C.; Young, M.; Walle, R.; Ismar, S.M.H. 2015. Using miniaturised radiotelemetry to discover the breeding grounds of the endangered New Zealand storm petrel Fregetta maoriana. Ibis 157: 754-766.

Robertson, H.A.; Dowding, J.E.; Elliott, G.P.; Hitchmough, R.A.; Miskelly, C.M.; O'Donnell, C.F.J.; Powlesland, R.G.; Sagar, P.M.; Scofield, R.P.; Taylor, G.A. 2013. Conservation status of New Zealand birds, 2012. New Zealand Threat Classification Series 4. Wellington, Department of Conservation.

Sullivan, W.; Wilson, K.J. 2001. Use of burrow flaps to minimise interference to Chatham petrel (Pterodroma axillaris) chicks by broad-billed prions (Pachyptila vittata). New Zealand Journal of Ecology 25: 71-75.

Taylor, G.; Cockburn, S.; Palmer, D.; Liddy, P. 2012. Breeding activity of Chatham Island taiko (Pterodroma magentae) using PIT tag recorders. New Zealand Journal of Ecology 36: 425-432.

Taylor, G.; Cole, R. 2002. South Georgian diving petrel (Pelecanoides georgicus) survey, Codfish Island/Whenua Hou. Wellington, Department of Conservation.

Taylor, G.A. 2000. Action Plan for Seabird Conservation in New Zealand. Wellington, Department of Conservation.

Taylor, G.A. 2013. South Georgian diving petrel. In Miskelly, CM. (ed.) New Zealand Birds Online. www. nzbirdsonline.org.nz (downloaded on 20 May 2016).

Towns, D.R; Broome, K.G. 2003. From small Maria to 
massive Campbell: forty years of rat eradications from New Zealand islands. New Zealand Journal of Zoology 30: 377-398.

Trainor, S. 2008. Codfish Island South Georgian diving petrel: a summary of field observations 2004-2007 and recommendations for future management. Southland Conservancy, Department of Conservation.

Wickham H. 2009. ggplot2: Elegant Graphics for Data Analysis. New York, Springer-Verlag.
Young, M. 2013. The breeding biology of northern whitefaced storm petrels (Pelagodroma marina maoriana) and a feeding trial in preparation for translocation, New Zealand. Unpubl. MSc thesis, Massey University, Palmerston North, New Zealand.

Zangmeister, J.L.; Hausmann, M.F.; Cerciara, J.; Mauck, R.A. 2009. Incubation failure and nest abandonment by Leach's storm-petrels detected using PIT tags and temperature loggers. Journal of Field Ornithology 80: 373-379. 